\title{
Efficacy of Tumor Necrosis Factor Inhibitors in Patients With Ankylosing Spondylitis
}

\author{
Deniz DÜLGEROĞLU ERDOĞDU, Ajda BAL, Özgür KARAAHMET, Sibel ERKOÇ, \\ Tuğba YALÇIN, Aytül ÇAKCI \\ Department of Physical Medicine and Rehabilitation, Dışkapı Yıldırım Beyazıt Training and Research Hospital, Ankara, Turkey
}

\begin{abstract}
Objectives: This study aims to investigate the efficacy of tumor necrosis factor-alpha blockers such as infliximab, etanercept, and adalimumab in the treatment of ankylosing spondylitis.

Patients and methods: The outcome of tumor necrosis factor-alpha blocker treatment was analyzed retrospectively in 59 patients with ankylosing spondylitis who were being treated in our clinic during last nine years. The patients' Assessment of SpondyloArthritis International Society (ASAS) 20 and ASAS 40 response rates, adverse drugs effects, and treatment compliance were evaluated.

Results: ASAS 20 response was achieved by $89.8 \%$ of the patients in the third month, and by $93.2 \%$ in the sixth month. ASAS 40 response was achieved by $61 \%$ of the patients in the third and sixth month. No statistically significant difference was detected between the three tumor necrosis factor-alpha blockers with regards to the ASAS 40 response rates. Mild infections, observed in 31 of the patients, were the most common side effects. Serious side effect was observed in only one patient. The number of patients who withdrew from the treatment for various reasons was six.

Conclusion: Treatment with infliximab, etanercept, or adalimumab is clinically effective and safe.

Keywords: Ankylosing spondylitis; treatment; tumor necrosis factors- $\alpha$ blockers.
\end{abstract}

Ankylosing spondylitis (AS) is a systemic and chronic inflammatory rheumatic disease of the axial skeleton including the spine and sacroiliac joints. Extra-spinal features include peripheral arthritis, uveitis, enteritis, and psoriasis. ${ }^{1}$ The prevalence of AS, which is the prototype of the spondyloarthritis, is $0.1-1.1 \%$ and it affects men at a higher rate than women, and usually starts in the third decade of life. ${ }^{2}$ Traditional disease modifying anti-rheumatic drugs (DMARDs) are usually ineffective for the spinal component of the disease. Exercise therapy and non-steroidal antiinflammatory drugs (NSAIDs) are the mainstay of the treatment. ${ }^{1,3,4}$

Over the last decade, dramatic improvements in the therapeutic field of AS have been achieved. Tumor necrosis factor-alpha (TNF- $\alpha$ ) blockers have been introduced in many studies as a novel and effective alternative for the treatment of AS patients who are refractory to NSAIDs and DMARDs. ${ }^{5-7}$ An optimal treatment for AS should target both symptomatic relief of pain, stiffness and fatigue, offering biological benefits for the reduction or prevention of joint damages and ankylosis. ${ }^{3}$ Recent randomized controlled studies conducted with TNF blockers have demonstrated that these drugs are effective in the treatment of spinal pain, limited mobility and function, and also extra-spinal involvement. ${ }^{5,8,9}$ In clinical practice, however, the optimal duration for use of these agents and the safety profile of TNF blockers have not been elucidated yet. In the update version of the literature review on the treatment with biologics, Baraliakos et al. ${ }^{10}$ showed strong evidences on the long-term efficacy and safety of TNF blockers in AS patients. In another study, 
Baraliakos et al. ${ }^{9}$ provided treatment outcomes of TNF blockers at eight years of treatment.

Despite reduced vertebral inflammation and improved sacroiliac joint as assessed by magnetic resonance imaging, there is currently no evidence regarding the prevention and decrease of structural damage by TNF blockers. ${ }^{11-13}$ In the Ankylosing Spondylitis Study for the Evaluation of Recombinant Infliximab Therapy, the authors reported no statistically significant difference in radiological damage among patients on infliximab (INF) and non-receiving patients at the end of two years, and that INF did not inhibit structural damage. ${ }^{14}$ In a two-year study including 41 AS patients on INF and 41 AS patients on conventional agents, Baraliakos et al. ${ }^{15}$ re-assessed the patients at baseline and at two years of the study. The authors identified decreased modified Stoke Ankylosing Spondylitis Spinal Scores in the group treated with INF. ${ }^{15}$ On the other hand, van der Heijde et $a .^{16}$ assessed the radiographs of patients with AS who received adalimumab (ADA) $(n=37)$ and those who did not receive any TNF blocker at baseline and at two years. The authors found no statistically significant difference in the modified Stoke Ankylosing Spondylitis Spinal Scores. In 2009, the SpondyloArthritis International Society (ASAS) and the European League Against Rheumatism agreed for a second update of the recommendations for the management of AS, and the use of anti-TNF agents. ${ }^{10}$

In this article, we aimed to present our clinical experience over the last decade regarding the use of anti-TNF- $\alpha$ drugs in the management of AS.

\section{PATIENTS AND METHODS}

Between March 2003 and December 2012, medical files of 59 patients (43 males; mean age $38.76 \pm 1.38$ years; range 18 to 60 years and 16 females; mean age $43.00 \pm 1.36$ years; range 32 to 50 years) at the age of $\geq 18$ who were diagnosed with AS according to the modified New York criteria ${ }^{17}$ and treated with TNF blockers at Ankara Diskapi Yildirim Beyazit Education and Research Hospital, Physical Medicine and Rehabilitation Outpatient Clinic were retrospectively analyzed. Patients were divided into three groups according to the treatment they received including INF, etanercept (ETA), or ADA. Based on the recommendations of ASAS, ${ }^{18}$ treatment with one of the TNF blockers was initiated in patients with a high disease activity [defined as a Bath Ankylosing Spondylitis Disease Activity Index (BASDAI) $\geq 4 \mathrm{U}$ on a $0-10$ scale $],{ }^{19}$ despite treatment with at least two different NSAIDs for three months. For patients who had an induration of $\geq 5 \mathrm{~mm}$ in the purified protein derivative (PPD) test, tuberculosis (TB) prophylaxis with isoniazid $300 \mathrm{mg}$ daily was administered for nine months, followed by TNF blockers after a month. The standard doses of TNF blockers used were as follows: INF at a dose of $5 \mathrm{mg} / \mathrm{kg}$ on week 0 and 2 , and then given every six weeks; ETA at a dose of $25 \mathrm{mg}$ twice weekly or $50 \mathrm{mg}$ weekly; and ADA at a dose of $40 \mathrm{mg}$ given once every two weeks.

Demographic characteristics of the patients, disease duration, human leukocyte antigen B-27 (HLA-B27) status, hip involvement, the number of peripheral arthritis, extra-articular involvement, the presence of joint prosthesis, PPD test results and prophylaxis for TB were recorded. Concomitant use of DMARDs and NSAIDs as well as any interruption for DMARDs and NSAIDs use during the treatment with TNF blockers were noted. Drug-related adverse events (AEs) which occurred during treatment and any reason for treatment discontinuation were also documented. We also provided the treatment outcomes of TNF blockers at eight and nine years as well as the remission rates of patients on INF, ETA and ADA. The rate of treatment switch due to AEs, unresponsiveness and side effects of TNF blockers were also reported.

Clinical assessment of the patients during the follow-up period was performed by using a numeric rating scale scoring system between 0 and 10 in terms of disease activity (Bath Ankylosing Spondylitis Disease Activity Index; BASDAI), metrology (Bath Ankylosing Spondylitis Metrology Index; BASMI) and function (Bath Ankylosing Spondylitis Functional Index; BASFI). ${ }^{20}$ The Turkish versions of BASDAI and BASFI which underwent validity and reliability test were used. ${ }^{21,22}$ The enthesitis score was determined by examining 13 enthesitic localizations with Maastricht Ankylosing Spondylitis Enthesitis Score. Peripheral joint involvement was assessed based on the number of swollen joints (a total of 64 joints). Laboratory parameters for inflammation during the first three months of 
the treatment [erythrocyte sedimentation rate (ESR) and C-reactive protein (CRP)], and the patient global assessment (PGA) and the enthesis responses were recorded. The efficacy of TNF blockers were assessed by using the ASAS group core set of criteria for symptomatic improvement in AS defined as 20 and $40 \%$ response. ${ }^{23}$ Data are expressed in percentages. Clinical outcome assessments were performed at screening, baseline, and on week 3, 6, 12, 24, 48, 60, 72, 84, 96, and 108.

\section{Statistical analysis}

Statistical analysis was performed using SPSS for Windows, version 11.5 (SPSS Inc., Chicago, IL, USA) software program. The Shapiro-Wilk test was used to determine if the continuous variables were normally distributed. The Levene test was used to examine the homogeneity of variances. Data were expressed in mean \pm standard deviation (SD) or median (min. - max.), where applicable. One-way ANOVA was used to compare mean values between the groups, whereas the Kruskal-Wallis test was performed to compare median values. When the $p$ value in the Kruskal-Wallis test was statistically significant, the Conover's non-parametric multiple comparison test was used to determine the differences between the groups. Categorical data were analyzed by Pearson's Chi-square, Fisher's exact or Likelihood ratio tests. The Wilcoxon signed-rank test was used to compare measurement times for continuous data between the groups, while the McNemar's test was used for nominal variables. A $p$ value of $<0.05$ was considered statistically significant. However, in all possible multiple comparisons, The Bonferroni correction was applied to check type I errors.

\section{RESULTS}

The baseline demographic and clinical characteristics of the patients with AS who were prescribed TNF blockers are shown in Table 1 . The median duration of the disease was 16 years. There was no significant difference in age, sex, disease duration, the number of peripheral arthritis, hip involvement, PPD test results and prophylaxis for TB. The mean PPD test value was $10.66 \mathrm{~mm}$ (range, 0-22 $\mathrm{mm}$ ) and TB prophylaxis was administered in 41 patients (69.49\%). The difference in the duration of drug use between the INF and ADA group and also between the ETA and ADA group were statistically significant $(p<0.001$ and $p=0.002$, respectively). The mean $\mathrm{PPD}$ test value was higher in the ETA group (13 $\mathrm{mm})$.

The HLA-B27 test was performed on only 16 patients and 15 were positive. Based on the extra-articular involvement assessment on admission, there was osteoporosis in five patients (8.47\%), pulmonary involvement in four $(6.77 \%)$, uveitis in seven (11.86\%), psoriasis in two (3.38\%) and inflammatory bowel disease in two (3.38\%). The most frequent AS-related extra-articular condition was uveitis. Three patients (5.08\%) had undergone bilateral hip replacement surgery, while two (3.38\%) had undergone unilateral hip replacement surgery. Two patients (3.38\%) had a

Table 1. Demographic and clinical features of patients according to tumor necrosis factors blockers

\begin{tabular}{|c|c|c|c|c|c|c|c|c|c|c|c|c|c|c|c|c|}
\hline \multirow[t]{2}{*}{ Parameters } & \multicolumn{5}{|c|}{$\begin{array}{c}\text { Infliximab } \\
(\mathrm{n}=21 ; 35.6 \%)\end{array}$} & \multicolumn{5}{|c|}{$\begin{array}{c}\text { Etanercept } \\
(\mathrm{n}=21 ; 35.6 \%)\end{array}$} & \multicolumn{5}{|c|}{$\begin{array}{l}\text { Adalimumab } \\
(\mathrm{n}=17 ; 28.8 \%)\end{array}$} & \multirow[b]{2}{*}{$p$} \\
\hline & $\mathrm{n}$ & $\%$ & Mean \pm SD & Med. & Min.-Max. & $\mathrm{n}$ & $\%$ & Mean \pm SD & Med. & Min.-Max. & $\mathrm{n}$ & $\%$ & Mean \pm SD & Med. & Min.-Max. & \\
\hline Age (year) & & & $38.6 \pm 8.0$ & & & & & $42.8 \pm 6.1$ & & & & & $38.1 \pm 10.6$ & & & $0.152 \dagger$ \\
\hline Sex & & & & & & & & & & & & & & & & $0.548 \neq$ \\
\hline Male & 14 & 66.7 & & & & 15 & 71.4 & & & & 14 & 82.4 & & & & \\
\hline Female & 7 & 33.3 & & & & 6 & 28.6 & & & & 3 & 17.6 & & & & \\
\hline $\begin{array}{l}\text { Duration of disease } \\
\text { (year) }\end{array}$ & & & & 14 & $5-30$ & & & & 17 & $4-36$ & & & & 15 & $4-30$ & 0.260 वा \\
\hline Hip involvement & 13 & 61.9 & & & & 9 & 42.9 & & & & 6 & 35.3 & & & & $0.229 \neq$ \\
\hline $\begin{array}{l}\text { Associated peripheral } \\
\text { arthritis }\end{array}$ & 10 & 47.6 & & & & 12 & 57.1 & & & & 10 & 58.8 & & & & $0.746 \neq$ \\
\hline $\begin{array}{l}\text { Duration of drugs } \\
\text { (months) }\end{array}$ & & & & 48 & $12-101^{a}$ & & & & 48 & $12-108^{b}$ & & & & 23 & $6-60^{\mathrm{a}, \mathrm{b}}$ & 0.0099 \\
\hline PPD (mm) & & & & 8 & $0-22$ & & & & 13 & $0-21$ & & & & 11 & $2-18$ & 0.1199 \\
\hline Prophylaxis & 12 & 57.1 & & & & 17 & 81.0 & & & & 12 & 70.6 & & & & $0.244 \neq$ \\
\hline
\end{tabular}


Table 2. Distribution of the enthesitis scores and the patient global assessment, erythrocyte sedimentation rate and $\mathrm{C}$-reactive protein values according to the groups at baseline and third month

\begin{tabular}{|c|c|c|c|c|c|c|c|c|}
\hline \multirow[t]{2}{*}{ Variables } & \multicolumn{2}{|c|}{ Baseline } & \multicolumn{2}{|c|}{ Third month } & \multirow[b]{2}{*}{$p \dagger$} & \multicolumn{2}{|c|}{ Change } & \multirow[b]{2}{*}{$p \neq$} \\
\hline & Mean & Min.-Max. & Mear & Min.-Max. & & Mean & Min.-Max. & \\
\hline Enthesitis score & & & & & & & & 0.294 \\
\hline Infliximab & 0 & $0-8$ & 0 & $0-19$ & 0.371 & 0 & $-8-17$ & \\
\hline Etanercept & 1 & $0-9$ & 0 & $0-3$ & 0.003 & -1 & $-6-0$ & \\
\hline Adalimumab & 0 & $0-9$ & 0 & $0-9$ & 0.041 & 0 & $-4-0$ & \\
\hline Patient global assessment & & & & & & & & 0.765 \\
\hline Infliximab & 7 & $1-10$ & 3 & $0-5$ & $<0.001$ & -4 & $-8-0.5$ & \\
\hline Etanercept & 7 & 3-9 & 2.5 & $1-5.5$ & $<0.001$ & -4 & $-7-0.5$ & \\
\hline Adalimumab & 5 & $4-8$ & 1 & $0-30$ & 0.007 & -4 & $-7-26$ & \\
\hline Erythrocyte sedimentation rate & & & & & & & & 0.562 \\
\hline Infliximab & 24 & $6-88$ & 8 & $1-37$ & $<0.001$ & -11.3 & $-70-3$ & \\
\hline Etanercept & 34 & 3-92 & 14 & $3-63$ & $<0.001$ & -19 & $-76-13$ & \\
\hline Adalimumab & 20 & $1-87$ & 14 & $3-26$ & 0.005 & -7 & $-66-6$ & \\
\hline C-reactive protein & & & & & & & & 0.839 \\
\hline Infliximab & 13 & 3-114 & 3 & $0.4-32$ & 0.002 & -7 & $-109-8$ & \\
\hline Etanercept & 12 & $2-189$ & 4 & $0.8-56$ & 0.002 & -6 & $-99-35$ & \\
\hline Adalimumab & 11.5 & $1-61.6$ & 3 & 1-25.5 & 0.002 & -8.5 & $-52.6-0$ & \\
\hline
\end{tabular}

history of TB and had been treated with anti-TB medications.

The enthesitis scores and changes from baseline in PGA, ESR and CRP values at three months of TNF blocker treatment are shown in Table 2. A statistically significant improvement in PGA, ESR and CRP was observed with each of the three TNF blockers. A statistically significant decrease in the enthesitis score at the end of the third month was observed only in patients on ETA $(p=0.003)$.
Regardless of the TNF blockers used, changes from baseline in the measurements of BASDAI, BASFI and BASMI at various follow-up periods are shown in Table 3. According to these changes, a statistically significant decrease in the BASDAI, BASFI and BASMI scores of 59 patients was observed at three and six months. This decrease continued up to 72 months for the BASDAI and BASFI, and up to 48 months for the BASMI. A total of 59 patients were under follow-up at six months, while 31 patients were under follow-up at

Table 3. Amount of change in the Bath Ankylosing Spondylitis Disease Activity Index, Bath Ankylosing Spondylitis Functional Index and Bath Ankylosing Spondylitis Metrology Index values in all patients from the third month of follow-up until the end of the follow-up, and the evaluation of these changes compared to baseline

\begin{tabular}{|c|c|c|c|c|c|c|c|c|c|}
\hline \multirow[b]{2}{*}{ Variables } & \multicolumn{3}{|c|}{ BASDAI } & \multicolumn{3}{|c|}{ BASFI } & \multicolumn{3}{|c|}{ BASMI } \\
\hline & $\mathrm{n}$ & Mean \pm SD & $p \dagger$ & $\mathrm{n}$ & Mean \pm SD & $p^{\dagger}$ & $\mathrm{n}$ & Mean \pm SD & $p^{\dagger}$ \\
\hline \multicolumn{10}{|l|}{ Month } \\
\hline $3^{\text {rd }}$ & 59 & $-3.56 \pm 1.75$ & $<0.0001$ & 59 & $-2.39 \pm 1.90$ & $<0.0001$ & 59 & $-0.86 \pm 1.27$ & $<0.0001$ \\
\hline $6^{\text {th }}$ & 59 & $-4.04 \pm 1.84$ & $<0.0001$ & 59 & $-3.02 \pm 1.95$ & $<0.0001$ & 59 & $-1.07 \pm 1.48$ & $<0.0001$ \\
\hline $12^{\text {th }}$ & 56 & $-4.20 \pm 1.96$ & $<0.0001$ & 56 & $-3.27 \pm 2.00$ & $<0.0001$ & 56 & $-1.09 \pm 1.21$ & $<0.0001$ \\
\hline $24^{\text {th }}$ & 43 & $-4.07 \pm 2.05$ & $<0.0001$ & 43 & $-3.60 \pm 2.19$ & $<0.0001$ & 43 & $-1.12 \pm 1.43$ & $<0.0001$ \\
\hline $36^{\text {th }}$ & 40 & $-4.12 \pm 1.89$ & $<0.0001$ & 40 & $-3.75 \pm 1.80$ & $<0.0001$ & 40 & $-1.03 \pm 1.44$ & 0.0002 \\
\hline $48^{\text {th }}$ & 31 & $-4.46 \pm 1.81$ & $<0.0001$ & 31 & $-3.79 \pm 1.72$ & $<0.0001$ & 31 & $-1.16 \pm 1.44$ & 0.0005 \\
\hline $60^{\text {th }}$ & 24 & $-4.79 \pm 1.80$ & $<0.0001$ & 24 & $-4.42 \pm 1.61$ & $<0.0001$ & 24 & $-1.04 \pm 1.57$ & 0.0047 \\
\hline $72^{\text {nd }}$ & 15 & $-5.31 \pm 1.86$ & 0.0006 & 15 & $-4.49 \pm 1.82$ & 0.0006 & 15 & $-1.07 \pm 1.62$ & 0.0304 \\
\hline $84^{\text {th }}$ & 21 & $-5.60 \pm 2.11$ & 0.0022 & 12 & $-3.79 \pm 1.54$ & 0.0022 & 12 & $-0.67 \pm 1.07$ & 0.0537 \\
\hline $96^{\text {th }}$ & 5 & $-4.94 \pm 2.51$ & 0.0431 & 6 & $-3.41 \pm 1.43$ & 0.0277 & 6 & $-1.33 \pm 1.37$ & 0.0707 \\
\hline $108^{\text {th }}$ & 1 & $-2.50 \pm 0$ & - & 1 & $-3.50 \pm 0$ & - & 1 & $-2.00 \pm 0$ & - \\
\hline
\end{tabular}

BASDAI: Bath Ankylosing Spondylitis Disease Activity Index; BASFI: Bath Ankylosing Spondylitis Functional Index; BASMI: Bath Ankylosing Spondylitis Metrology Index; SD: Standard deviation; $\uparrow p<0.0008$ was accepted as statistically significant for the Wilcoxon rank test, the Bonferroni correction. 


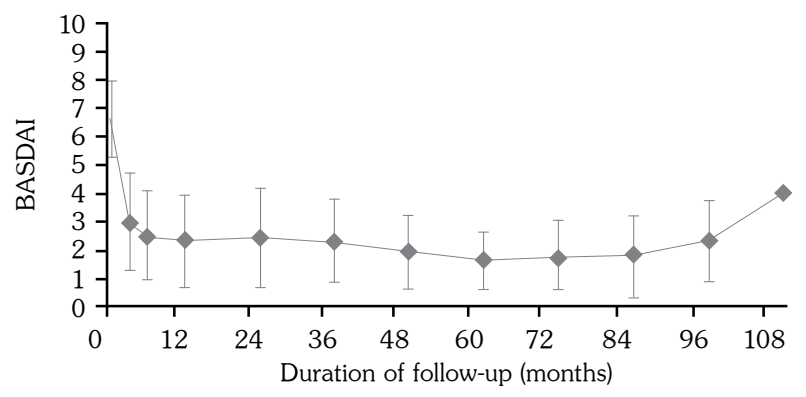

Figure 1. Bath Ankylosing Spondylitis Disease Activity Index with respect to the follow-up periods.

48 months. Only one patient was under follow-up at 108 months. Changes from baseline in the BASDAI score during the follow-up period are shown in Figure 1.

A total of $89.8 \%$ and $93.2 \%$ patients achieved ASAS 20 response at three months and at six months, respectively. There was no statistically significant difference in the ASAS 20 response rates among the three TNF blockers. The number of patients who achieved ASAS 40 response was $61.0 \%$ at three and six months. There was no statistically significant difference in the ASAS 40 response rates among the three TNF blockers. The ASAS 40 response rates with INF, ETA and ADA treatment during the follow-up period are shown in Figure 2.

Although 54 patients (77.14\%) (11 methotrexate, 43 sulphasalazine) were using concomitant DMARDs at the initial TNF blocker treatment, 14 patients (20\%) (3 methotrexate, 11 sulphasalazine) discontinued DMARDs. While 32 patients (54.23\%) were using NSAIDs concomitantly at the initial of the treatment, six patients (10.16\%) discontinued NSAIDs. Twelve patients $(20.33 \%)$ were switched to a second TNF blocker drug, while one patient (1.69\%) used all three drugs. Of three patients who had INFrelated infusion reactions, two were switched to ETA and one to ADA. Three patients who were unresponsive to the treatment were also switched to ETA. Two patients who were on INF treatment were switched to ETA due to increased liver transaminase level in one and psoriasis in the other. One of two patients on ETA treatment was prescribed ADA, while one was prescribed INF due to the unresponsiveness to ETA treatment. One patient who was on ETA treatment was switched to ADA due to psoriasis. One patient was also switched from ETA to INF due to uveitis. One patient who had INF-related infusion reactions and switched to ETA was prescribed ADA as a third-line biologic.

One patient on a TNF blocker discontinued treatment due to skin $\mathrm{TB}$, one female patient due to the willingness to become pregnant, one male patient due to the willingness to be father, two patients due to non-compliance with treatment, and one patient due to the lack of response.

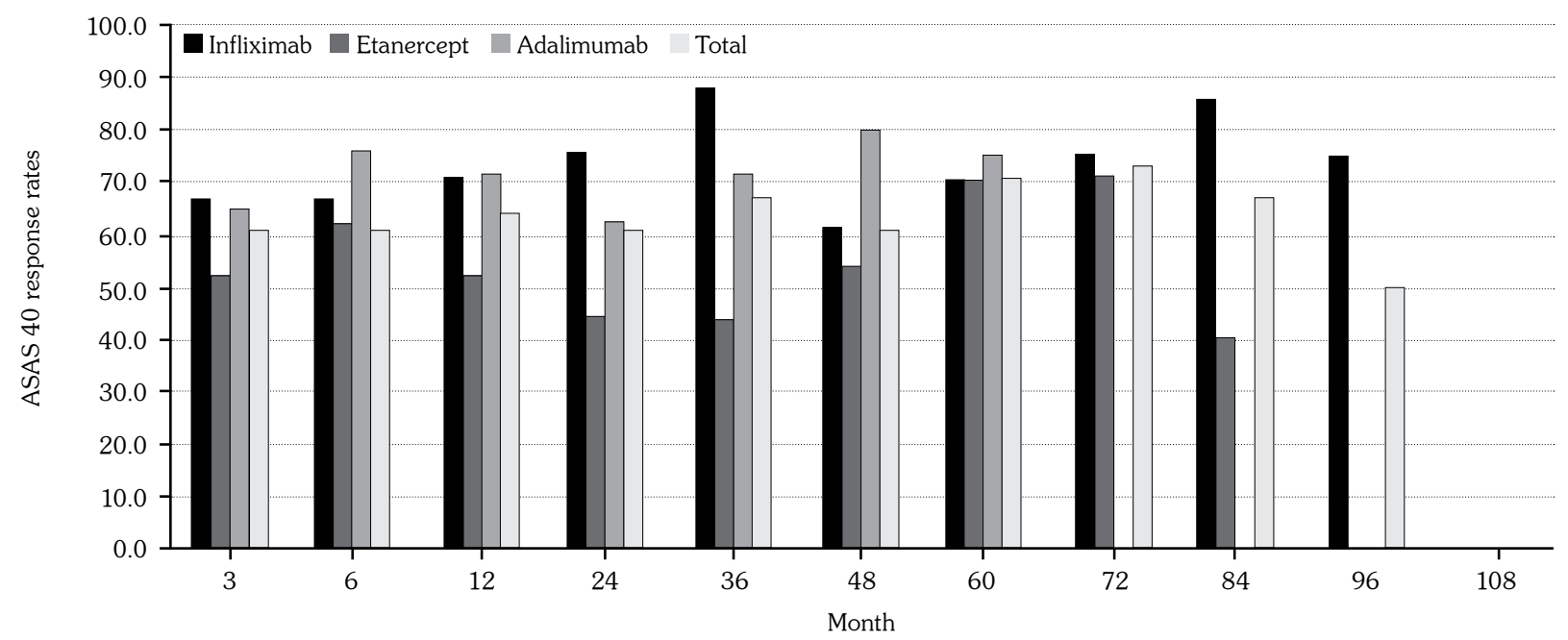

Figure 2. The SpondyloArthritis International Society 40 response rates. 


\begin{tabular}{|c|c|c|c|c|c|}
\hline \multirow[t]{2}{*}{ All adverse events } & \multirow{2}{*}{$\frac{\text { Infliximab }}{n}$} & \multirow{2}{*}{$\frac{\text { Etanercept }}{\mathrm{n}}$} & \multirow{2}{*}{$\frac{\text { Adalimumab }}{\mathrm{n}}$} & \multicolumn{2}{|c|}{ Total (\% of all AEs) } \\
\hline & & & & $\mathrm{n}$ & $\%$ \\
\hline Infusion reaction & 3 & & & 3 & 4.28 \\
\hline Headache & & 1 & 1 & 2 & 2.85 \\
\hline \multicolumn{6}{|l|}{ Skin allergic reactions } \\
\hline Itching/eruption & 4 & 5 & 2 & 11 & 15.71 \\
\hline Hair loss & 1 & & & 1 & 1.42 \\
\hline Oral ulcers & & & 1 & 1 & 1.42 \\
\hline Elevation of liver enzymes & 2 & 3 & 1 & 6 & 8.57 \\
\hline Elevation of creatinine & 1 & & & 1 & 1.42 \\
\hline Elevation of bilirubin & 1 & & & 1 & 1.42 \\
\hline \multicolumn{6}{|l|}{ Mild infections } \\
\hline Skin infection & 3 & 1 & & 4 & 5.71 \\
\hline Upper respiratory infection & 4 & 2 & 3 & 9 & 12.85 \\
\hline Influenza & 2 & 3 & & 5 & 7.14 \\
\hline Pulmonary infection & 5 & 2 & 1 & 8 & 11.42 \\
\hline Urinary tract infection & 3 & 2 & & 5 & 7.14 \\
\hline \multicolumn{6}{|l|}{ Severe/opportunistic infections } \\
\hline Skin tuberculosis & & 1 & & 1 & 1.42 \\
\hline Uveitis & 4 & 3 & 2 & 9 & 12.85 \\
\hline Psoriasis & 1 & 1 & & 2 & 2.85 \\
\hline Kidney stone & 3 & & & 3 & 4.28 \\
\hline
\end{tabular}

The AEs which occurred during the follow-up period are summarized for an individual drug in Table 4. A total of $70 \mathrm{AEs}$ were identified in all patients, of which 31 were mild infections. The most frequent infections were upper respiratory infections (URIs) (12.85\%) and pulmonary infections (11.42\%). Nine patients had uveitis and two patients had psoriasis. Patients with uveitis were switched from a TNF blocker to another. Among all drugs used, only ETA was interrupted, due to the development of skin TB.

The study included patients who were diagnosed earlier and newly, and under follow-up for nine years receiving biological agents. The number of earlier patients who were under follow-up for nine, eight and seven years was low. Some of them withdrew from the study due to side effects or unresponsiveness to the treatment over time. The higher number of newly patients who were under follow-up for three, six and 12 months may be explained by a higher prescription rate of biological agents in recent years.

\section{DISCUSSION}

In our study, we report the treatment outcomes of three TNF blockers which were used in the management of AS in 59 patients who were under follow-up for nine years. The duration of follow-up ranged between three months at the early stage and 108 months at the late stage. A total of 59 patients and 43 patients (72.88\%) completed a three-month and 24-month follow-up, while 31 patients (52.54\%) were under follow-up up to 48 months. Six patients completed a 96-month follow-up, whereas one patient completed a 108-month follow-up. We observed that compliance to the treatment was overall good, except in six patients who discontinued TNF blocker use.

In a study including 69 patients with AS on INF treatment $(n=30)$ or placebo $(n=35)$, Baraliakos et al. ${ }^{9}$ reported that 65 patients (94\%), 38 patients (55\%) and 33 patients (48\%) continued treatment for three months, five years and eight years respectively. Patients who completed eight-year treatment had a lower disease activity and good functional capacity.

In another study including 201 AS patients who were treated with INF for two years, van der Heijde et al. ${ }^{24}$ reported that $61 \%$ of the patients had ASAS 20 response on week 24, compared to $19 \%$ of the patients on placebo. In addition, Haibel et al. ${ }^{25}$ administered ADA $40 \mathrm{mg}$ to $14 \mathrm{AS}$ patients on alternate weeks over 52 weeks. A total of $70 \%$ of the patients had improved function, nocturnal pain and PGA, with 50\% reporting a substantial ASAS 50 response. The authors also 
reported that $86 \%$ of the patients achieved ASAS 20 response at week 20 . The number of patients achieving ASAS 20 response in our study was highest for six months. Fifty-five patients (93.2\%) achieved ASAS 20 responses. No difference in the ASAS 20 response rate was observed among the three TNF blockers. Based on the ASAS 40 response rates, 36 patients (61\%) achieved remission at three, six and 12 months, indicating no differences in the effectiveness of the drugs.

In a multi-center trial, van der Heijde et al. ${ }^{26}$ administered $40 \mathrm{mg}$ ADA on alternate weeks to 208 AS patients who were refractory to secondline agents such as NSAIDs and methotrexate. A total of $30 \%$ of the patients completed the study and a significantly greater ASAS 20 response was observed on week 12 in $58.2 \%$ of the patients on ADA, compared to those receiving placebo. Significant improvement in spinal mobility was observed based on the BASMI and enthesis score on week 12 and 24 . No serious side effects were observed. ${ }^{26}$

Coates et al. $^{5}$ conducted a study including 113 patients using either INF, ETA or ADA. The mean duration for use of TNF blockers was 21 (range 1 to 88) months. A relatively high proportion of patients (35\%) were receiving concomitant DMARDs. A total of $8.0 \%$ of the patients $(n=9)$ had serious side effects or allergy requiring the interruption or switching of the therapy. The mean BASDAI decreased from 6.57 to 3.12, while the mean BASFI decreased from 6.45 to 4.16 . The mean CRP decreased from 31 to $7 \mathrm{~g} / \mathrm{dL}$. Thirty three patients were treated with a single medication for 24 months and decreased BASDAI, BASFI and CRP values more than $>20 \mathrm{~g} / \mathrm{dL}$ were achieved. ${ }^{5}$ In our study, the initial rate of concomitant DMARDs and NSAIDs at baseline was $91.52 \%$ and $54.23 \%$, respectively. During treatment with any one of these three drugs, $23.72 \%$ of the patients discontinued DMARDs, while 10.16\% discontinued NSAIDs. On the other hand, the mean decrease in BASDAI, BASFI and BASMI values were $4.46,3.79$ and 1.16 , respectively in 31 patients who completed a 48-month follow-up period. Pain relief and improved function with a significant decrease in ESR and CRP values, the indicators of inflammation, were observed in these patients.
Martin-Mola et al. ${ }^{27}$ treated 59 AS patients with ETA, and 37 patients (62.7\%) completed a three-year study. Of 14 patients, the reasons for discontinuation were AEs for seven patients (23.7\%), unresponsiveness in one patient (1.7\%), and other causes in six patients (10.2\%). One patient with a history of heart disease developed myocardial infarction (MI) and cholelithiasis, leading to death. Another patient died due to MI at five months following the discontinuation of ETA. One patient died at one month due to MI and multiple organ failure. Four patients were excluded due to serious infections including acute infection of the sigmoid colon in one patient, pneumonia leading to sepsis in one patient, and human immunodeficiency virus seropositivity in another patient. The authors also reported three cancer cases who were diagnosed during the study, including metastatic prostate carcinoma, squamous cell carcinoma of the skin, and chronic lymphoid leukemia. ${ }^{27}$ In our study, we assessed TNF blocker-related AEs and found INF-related infusion reactions in three patients. However, these patients received outpatient treatment. Two of them were switched to ETA, while one was switched to ADA. Allergic skin reactions were also observed in 11 patients with a higher rate in patients on ETA. A total of $12.85 \%$ of the patients had URIs which were the most frequently seen mild infections in our study, indicating a lower incidence compared to the literature data. Upper respiratory infection is the most common $\mathrm{AE}$ in the literature. ${ }^{26,28-30}$ Braun et al. $^{6}$ reported that $51 \%$ of the patients who were on INF treatment and $35 \%$ of the patients in the placebo group had URIs. Baraliakos et al. ${ }^{10}$ reported that the incidence of mild infection was 84.5(58.4)/100 per subject year in three TNF blocker groups, while it was 63.6(63.0)/100 per subject year in the placebo group. The authors also suggested that the incidence of infection decreased with a long-term treatment, indicating no significant difference among INF, ETA, and ADA treatment. Martin-Mola et al. ${ }^{27}$ also reported that 44 patients (96\%) who were on INF treatment had an AE at least and the most common AE was URI (37\%). In our study, one male patient developed a skin TB requiring treatment discontinuation. The ETA treatment was interrupted and the patient was given anti-TB treatment. At baseline, he was not initiated TB prophylaxis, as the PDD test result was $1 \mathrm{~mm}$. Skin TB developed at eight years of 
treatment. Turkey is one of the endemic areas for $\mathrm{TB}$ in the world with a higher incidence than the Western countries. ${ }^{31}$ Two patients (3.38\%) were previously diagnosed with TB and treated with a full dose of anti-TB medications. The mean PDD test value was $10.66 \mathrm{~mm}$ (range 0 to $22 \mathrm{~mm}$ ) in our study, and 41 patients (69.49\%) underwent TB prophylaxis. ${ }^{6,9}$

Uveitis was observed in nine patients (12.85\%) during treatment, including one with frequent uveitis episodes prior to the initiation of the TNF blocker treatment. One patient was on ETA and switched to INF after an episode of uveitis. Due to another uveitis episode with INF, the patient was switched to ADA, which led to another uveitis episode. ${ }^{5}$ Braun et al. ${ }^{32}$ reported that the incidence of acute anterior uveitis per 100 patient years was 15.6 in the placebo group, and 6.8 per 100 patient year in the anti-TNF group. The INF treatment was also reported to inhibit the exacerbation of uveitis. ${ }^{32}$ Baraliakos et al. ${ }^{9}$ reported that 12 of 33 patients who were on INF treatment had acute anterior uveitis at baseline, and four patients had six exacerbation episodes at eight years of treatment. On the other hand, the authors did not observe any new-onset acute anterior uveitis. Martin-Mola et al. ${ }^{27}$ reported that 10 of 20 patients who were on ETA had $\geq 1$ exacerbation episode of uveitis and two patients had new-onset uveitis. None of the patients discontinued treatment. In a registry-based study conducted in 2007, there were 43 reported cases of uveitis associated with ETA, 14 associated with INF, and two associated with ADA. ${ }^{33}$ The incidence of ETA-associated uveitis was higher compared to INF treatment among TNF blockers $(p<0.01)$. This may be explained by its unique TNF-beta ( $\beta$ ) inhibitory effect. On the other hand, TNF- $\beta$ was associated with uveitis in animal studies. Therefore, ETA was expected to be effective in the treatment of uveitis. Compared to ETA, higher efficacy rate of INF in the treatment of extra-articular inflammatory diseases such as uveitis is another consideration. ${ }^{33}$ As a result, it has been suggested that the beneficial effect of ETA is low, and INF is far more effective in the control of uveitis in patients with AS. ${ }^{33,34}$

In our study, we observed psoriasis in one patient on INF and one patient on ETA, which was consistent with the literature., ${ }^{7,28,35}$ On the other hand, there is no case of kidney stones as an AE of INF treatment in the literature. However, kidney stones developed in three patients on INF in our study. This may be explained by regional and genetic differences.

In addition, the reason for the relatively lower incidence of $\mathrm{AEs}$ in patients on ADA can be attributed to the lower number of patients in this group and to the fact that this drug is newer. A total of 17 patients were on ADA, 21 on INF, and 21 on ETA treatments. The mean duration of ADA treatment was 23 months, while it was 48 months for INF and ETA treatment.

Baraliakos et al. ${ }^{9}$ reported that a total of 36 AS patients were withdrawn from study due to treatment-related $\mathrm{AEs}$. The most frequent $\mathrm{AE}$ was increased transaminase levels and anti-nuclear antibodies $(n=8)$, followed by infusion site reactions $(n=3)$ and unresponsiveness $(n=3)$. In addition, one patient was also withdrawn from the study for one of the following diagnoses or conditions: TB (during the first three months of the study), positive testing for $\mathrm{TB}$ and refusing prophylaxis treatment, development of allergic granulomatosis of the lung, pancreatitis and worsening of overall condition after infusions. ${ }^{9}$ Furthermore, six patients were excluded due to visiting other physicians, five due to expected pregnancy, two due to non-compliance and three due to unresponsiveness. Similarly, six patients discontinued treatment due to the following reasons in our study: the willingness to become pregnant in a female patient, the willingness to be father in a male patient, skin TB which was considered a serious side effect in one patient, non-compliance in two patients, and unresponsiveness in one patient.

There are some limitations in our study. These are particularly the lack of the HLA-B27 status in each patient, lack of antibody analysis in patients who were resistant to TNF blockers, and missing information on radiological damage of TNF blockers.

In conclusion, we did not observe serious infections, MI, cancer or neurodegenerative diseases such as multiple sclerosis with the TNF blocker treatment in our study. The number of patients who were lost to follow-up or who discontinued treatment was also low. Therefore, we conclude that the treatment of AS with any of the three TNF blockers may be safe with a high 
rate of patient compliance. These medications may be successful in most cases in improving the clinical findings of AS.

\section{Declaration of conflicting interests}

The authors declared no conflicts of interest with respect to the authorship and/or publication of this article.

\section{Funding}

The authors received no financial support for the research and/or authorship of this article.

\section{REFERENCES}

1. Toussirot E, Bertolini E, Wending D Management of ankilosing spondylitis with infliximab. Open Access Rheumatology Research and Reviews 2009;1:69-82.

2. Braun J, Baraliakos X, Brandt J, Listing J, Zink A, Alten $\mathrm{R}$, et al. Persistent clinical response to the anti-TNF-alpha antibody infliximab in patients with ankylosing spondylitis over 3 years. Rheumatology (Oxford) 2005;44:670-6.

3. Paul S, Keat A. Assessment of patients with spondyloarthropathies for treatment with tumour necrosis factor alpha blockade. Rheumatology (Oxford) 2005;44:17-23.

4. Bodur H, Sivas F, Yllmaz Ö, Özgöçmen S, Günaydın $\mathrm{R}$, Kaya T, et al. Turkish League against Rheumatism National Recommendations for the management of ankylosing spondylitis. Turk $J$ Rheumatol 2011;26:173-86.

5. Coates LC, Cawkwell LS, Ng NW, Bennett AN, Bryer DJ, Fraser $\mathrm{AD}$, et al. Real life experience confirms sustained response to long-term biologics and switching in ankylosing spondylitis. Rheumatology (Oxford) 2008;47:897-900.

6. Braun J, Brandt J, Listing J, Zink A, Alten R, Golder $\mathrm{W}$, et al. Treatment of active ankylosing spondylitis with infliximab: a randomised controlled multicentre trial. Lancet 2002;359:1187-93.

7. Dougados M, Braun J, Szanto S, Combe B, Geher P, Leblanc V, et al. Continuous efficacy of etanercept in severe and advanced ankylosing spondylitis: results from a 12-week open-label extension of the SPINE study. Rheumatology (Oxford) 2012;51:1687-96.

8. Vastesaeger N, van der Heijde D, Inman RD, Wang Y, Deodhar A, Hsu B, et al. Predicting the outcome of ankylosing spondylitis therapy. Ann Rheum Dis 2011;70:973-81.

9. Baraliakos X, Listing J, Fritz C, Haibel H, Alten R, Burmester GR, et al. Persistent clinical efficacy and safety of infliximab in ankylosing spondylitis after 8 years--early clinical response predicts long-term outcome. Rheumatology (Oxford) 2011;50:1690-9.
10. Baraliakos X, van den Berg R, Braun J, van der Heijde D. Update of the literature review on treatment with biologics as a basis for the first update of the ASAS/ EULAR management recommendations of ankylosing spondylitis. Rheumatology (Oxford) 2012;51:1378-87.

11. Maksymowych WP. Update on the treatment of ankylosing spondylitis. Ther Clin Risk Manag 2007;3:1125-33.

12. Sieper J, Baraliakos X, Listing J, Brandt J, Haibel $\mathrm{H}$, Rudwaleit $M$, et al. Persistent reduction of spinal inflammation as assessed by magnetic resonance imaging in patients with ankylosing spondylitis after 2 yrs of treatment with the anti-tumour necrosis factor agent infliximab. Rheumatology (Oxford) 2005;44:1525-30.

13. Baraliakos X, Brandt J, Listing J, Haibel H, Sörensen $\mathrm{H}$, Rudwaleit $\mathrm{M}$, et al. Outcome of patients with active ankylosing spondylitis after two years of therapy with etanercept: clinical and magnetic resonance imaging data. Arthritis Rheum 2005;53:856-63.

14. van der Heijde D, Landewé R, Baraliakos X, Houben $\mathrm{H}$, van Tubergen A, Williamson $\mathrm{P}$, et al. Radiographic findings following two years of infliximab therapy in patients with ankylosing spondylitis. Arthritis Rheum 2008;58:3063-70.

15. Baraliakos X, Listing J, Rudwaleit M, Brandt J, Sieper $J$, Braun J. Radiographic progression in patients with ankylosing spondylitis after 2 years of treatment with the tumour necrosis factor alpha antibody infliximab. Ann Rheum Dis 2005;64:1462-6.

16. van der Heijde DM, Revicki DA, Gooch KL, Wong RL, Kupper H, Harnam N, et al. Physical function, disease activity, and health-related quality-of-life outcomes after 3 years of adalimumab treatment in patients with ankylosing spondylitis. Arthritis Res Ther 2009;11:R124.

17. van der Linden S, Valkenburg HA, Cats A. Evaluation of diagnostic criteria for ankylosing spondylitis. A proposal for modification of the New York criteria. Arthritis Rheum 1984;27:361-8.

18. Braun J, Zochling J, Baraliakos X, Alten R, Burmester $\mathrm{G}$, Grasedyck K, et al. Efficacy of sulfasalazine in patients with inflammatory back pain due to undifferentiated spondyloarthritis and early ankylosing spondylitis: a multicentre randomised controlled trial. Ann Rheum Dis 2006;65:1147-53.

19. Garrett S, Jenkinson T, Kennedy LG, Whitelock H, Gaisford P, Calin A. A new approach to defining disease status in ankylosing spondylitis: the Bath Ankylosing Spondylitis Disease Activity Index. J Rheumatol 1994;21:2286-91.

20. Calin A, Garrett S, Whitelock H, Kennedy LG, O'Hea J, Mallorie P, et al. A new approach to defining functional ability in ankylosing spondylitis: the development of the Bath Ankylosing Spondylitis Functional Index. J Rheumatol 1994;21:2281-5.

21. Ay S, Kutlay Ş, Kurtayiş Y, Yanık B. Ankilozan spondilitli hastalarda Bath Ankilozan Spondilit Hastalk 
Aktivite indeksinin (BASHAI) Türkçe versiyonunun geçerlilik ve güvenilirlik çalışması. Romatizma 2004;19:139-46.

22. Karatepe AG, Akkoc Y, Akar S, Kirazli Y, Akkoc $\mathrm{N}$. The Turkish versions of the Bath Ankylosing Spondylitis and Dougados Functional Indices: reliability and validity. Rheumatol Int 2005;25:612-8.

23. Pham T, Landewé $R$, van der Linden $S$, Dougados $M$, Sieper J, Braun J, et al. An international study on starting tumour necrosis factor-blocking agents in ankylosing spondylitis. Ann Rheum Dis 2006;65:1620-5.

24. van der Heijde D, Dijkmans B, Geusens P, Sieper J, DeWoody K, Williamson $\mathrm{P}$, et al. Ankylosing Spondylitis Study for the Evaluation of Recombinant Infliximab Therapy Study Group. Efficacy and safety of infliximab in patients with ankylosing spondylitis: results of a randomized, placebo-controlled trial (ASSERT). Arthritis Rheum 2005;52:582-91.

25. Haibel H, Rudwaleit M, Brandt HC, Grozdanovic $\mathrm{Z}$, Listing J, Kupper $\mathrm{H}$, et al. Adalimumab reduces spinal symptoms in active ankylosing spondylitis: clinical and magnetic resonance imaging results of a fifty-two-week open-label trial. Arthritis Rheum 2006;54:678-81.

26. van der Heijde D, Kivitz A, Schiff MH, Sieper $\mathrm{J}$, Dijkmans BA, Braun $\mathrm{J}$, et al. Efficacy and safety of adalimumab in patients with ankylosing spondylitis: results of a multicenter, randomized, double-blind, placebo-controlled trial. Arthritis Rheum 2006;54:2136-46.

27. Martín-Mola E, Sieper J, Leirisalo-Repo M, Dijkmans BA, Vlahos B, Pedersen R, et al. Sustained efficacy and safety, including patient-reported outcomes, with etanercept treatment over 5 years in patients with ankylosing spondylitis. Clin Exp Rheumatol 2010;28:238-45.

28. Heldmann F, Brandt J, van der Horst-Bruinsma IE, Landewe R, Sieper J, Burmester GR, et al. The European ankylosing spondylitis infliximab cohort
(EASIC): a European multicentre study of long term outcomes in patients with ankylosing spondylitis treated with infliximab. Clin Exp Rheumatol 2011;29:672-80.

29. Sieper J, van der Heijde D, Dougados M, Mease PJ, Maksymowych WP, Brown MA, et al. Efficacy and safety of adalimumab in patients with nonradiographic axial spondyloarthritis: results of a randomised placebo-controlled trial (ABILITY-1). Ann Rheum Dis 2013;72:815-2.

30. Revicki DA, Luo MP, Wordsworth P, Wong RL, Chen N, Davis JC Jr; ATLAS Study Group. Adalimumab reduces pain, fatigue, and stiffness in patients with ankylosing spondylitis: results from the adalimumab trial evaluating long-term safety and efficacy for ankylosing spondylitis (ATLAS). J Rheumatol 2008;35:1346-53.

31. Pamuk ON, Yesil Y, Donmez S, Unlü E, Köker IH, Cakir N. The results of purified protein derivative test in ankylosing spondylitis patients: clinical features, HRCT results and relationship with TNF-blocker usage. Rheumatol Int 2008;29:179-83.

32. Braun J, Baraliakos X, Listing J, Sieper J. Decreased incidence of anterior uveitis in patients with ankylosing spondylitis treated with the anti-tumor necrosis factor agents infliximab and etanercept. Arthritis Rheum 2005;52:2447-51.

33. Lim LL, Fraunfelder FW, Rosenbaum JT. Do tumor necrosis factor inhibitors cause uveitis? A registrybased study. Arthritis Rheum 2007;56:3248-52.

34. Braun J, Baraliakos X, Listing J, Fritz C, Alten $R$, Burmester G, et al. Persistent clinical efficacy and safety of anti-tumour necrosis factor alpha therapy with infliximab in patients with ankylosing spondylitis over 5 years: evidence for different types of response. Ann Rheum Dis 2008;67:340-5.

35. Dijkmans B, Emery P, Hakala M, Leirisalo-Repo M, Mola EM, Paolozzi L, et al. Etanercept in the longterm treatment of patients with ankylosing spondylitis. J Rheumatol 2009;36:1256-64. 